\title{
Genomic analysis of Spanish wheat landraces reveals their variability and potential for breeding
}

\author{
Laura Pascual', Magdalena Ruiz², Matilde López-Fernández' ${ }^{1}$, Helena Pérez-Peña', Elena Benavente',
} José Francisco Vázquez ${ }^{1}$, Carolina Sansaloni ${ }^{3}$ and Patricia Giraldo ${ }^{1 *}$ (i)

\begin{abstract}
Background: One of the main goals of the plant breeding in the twenty-first century is the development of crop cultivars that can maintain current yields in unfavorable environments. Landraces that have been grown under varying local conditions include genetic diversity that will be essential to achieve this objective. The Center of Plant Genetic Resources of the Spanish Institute for Agriculture Research maintains a broad collection of wheat landraces. These accessions, which are locally adapted to diverse eco-climatic conditions, represent highly valuable materials for breeding. However, their efficient use requires an exhaustive genetic characterization. The overall aim of this study was to assess the diversity and population structure of a selected set of 380 Spanish landraces and 52 reference varieties of bread and durum wheat by high-throughput genotyping.
\end{abstract}

Results: The DArTseq GBS approach generated $10 \mathrm{~K} \mathrm{SNPs}$ and $40 \mathrm{~K}$ high-quality DArT markers, which were located against the currently available bread and durum wheat reference genomes. The markers with known locations were distributed across all chromosomes with relatively well-balanced genome-wide coverage. The genetic analysis showed that the Spanish wheat landraces were clustered in different groups, thus representing genetic pools providing a range of allelic variation. The subspecies had a major impact on the population structure of the durum wheat landraces, with three distinct clusters that corresponded to subsp. durum, turgidum and dicoccon being identified. The population structure of bread wheat landraces was mainly biased by geographic origin.

Conclusions: The results showed broader genetic diversity in the landraces compared to a reference set that included commercial varieties, and higher divergence between the landraces and the reference set in durum wheat than in bread wheat. The analyses revealed genomic regions whose patterns of variation were markedly different in the landraces and reference varieties, indicating loci that have been under selection during crop improvement, which could help to target breeding efforts. The results obtained from this work will provide a basis for future genome-wide association studies.

Keywords: Wheat improvement, Local germplasm, GBS, DArTseq markers, SNP, Genetic diversity, Population structure

\footnotetext{
* Correspondence: patricia.giraldo@upm.es

${ }^{1}$ Department of Biotechnology-Plant Biology, School of Agricultural, Food

and Biosystems Engineering, Universidad Politécnica de Madrid, Madrid,

Spain

Full list of author information is available at the end of the article
}

(c) The Author(s). 2020 Open Access This article is distributed under the terms of the Creative Commons Attribution 4.0 International License (http://creativecommons.org/licenses/by/4.0/), which permits unrestricted use, distribution, and reproduction in any medium, provided you give appropriate credit to the original author(s) and the source, provide a link to the Creative Commons license, and indicate if changes were made. The Creative Commons Public Domain Dedication waiver (http://creativecommons.org/publicdomain/zero/1.0/) applies to the data made available in this article, unless otherwise stated. 


\section{Background}

Wheat is a cereal that belongs to the Poaceae family. Wheat occupies a central place in human nutrition providing $20 \%$ of the daily protein and food calories of the human population. Currently cultivated wheat originated from natural hybridization events between different species [1]. Roughly 90 to $95 \%$ of the wheat produced in the world is common, or bread wheat (Triticum aestivum L.; $2 \mathrm{n}=6 \mathrm{x}=42,17 \mathrm{~Gb}$, AABBDD genomes). The remainder of the world's wheat production includes about 35-40 million tons of durum wheat (T. turgidum var. durum; $2 \mathrm{n}=4 \mathrm{x}=28,13 \mathrm{~Gb}, \mathrm{AABB}$ genomes), which is cultivated mainly in the Mediterranean region (http://www.fao.org/faostat/en/).

Advances in molecular biology and high-throughput genotyping technologies have significantly impacted the field of molecular plant breeding, leading to shift from a phenotype-based to a genotype-based selection [2]. The integrated use of genomic and molecular tools in conventional phenotype selection programs has allowed the development of new breeding strategies such as marker assisted selection (MAS) and genomic selection. However, in wheat, the large complex genome with an over $85 \%$ repetitive DNA content has hampered the application of these molecular breeding approaches compared to their use in other crops, as the presence of two or three separate but closely related subgenomes hinders the analysis of homoeologous gene sequences [3]. The recently published durum and bread wheat reference genomes $[4,5]$ provide high-quality data that will help to physically locate thousands of scattered molecular markers, thus facilitating the identification of key genes by genome-wide association studies (GWAS) that will be highly valuable for MAS in wheat breeding programs [6].

The successful genomics-assisted breeding of any crop will be enhanced by a thorough understanding of the species' genetic diversity. As is the case in other crops, genetic diversity of wheat has declined as a consequence of bottlenecks encountered during polyploidization and domestication [7, 8]. Modern plant breeding practices, in which only a small number of elite cultivars are included in crossing programs, have further narrowed the genetic base of wheat throughout the world, limiting the pool of alleles in which to search for new traits of agronomic interest. This has promoted wide crossing programs carried out since the 1980s at different centers of wheat research such as CIMMYT (Centro Internacional de Mejoramiento de Maíz y Trigo). Indeed, by 1990, CIMMYT breeders began to successfully increase wheat productivity and genetic diversity through the introgression of various novel wheat materials. However, the genetic diversity represented by current wheat cultivars needs to be further increased to face novel threats, such as climate change, which demands an enlarged pool of alleles. Fortunately, an enormous number of genetically different, locally well-adapted wheat landraces were generated through natural or farmer-mediated selection in the previous century. Because future gains in yield potential will surely require the exploitation of these largely untapped sources of genetic diversity [9], deep knowledge of their genetic/genomic diversity is highly valuable to address the forthcoming plant breeding challenges [10].

A large number of studies have been performed to estimate genetic diversity by employing different methodologies in diverse plant species [11, 12], including wheat [13]. It is accepted that molecular markers are the best option for genetic variation studies. Among these markers, single nucleotide polymorphisms (SNPs), whose detection has been enormously facilitated by high-throughput technologies such as SNP arrays [14] or genotyping-by-sequencing (GBS) [15], are the most frequently used for genome-wide diversity studies.

The assessment of genome-wide diversity by GBS provides robust estimates of diversity and has been increasingly adopted as a fast, high-throughput cost-effective tool for whole-genome genetic diversity analysis in large germplasm sets [16]. The DArTseq (Diversity Array Technology sequence) markers, based on GBS [17], efficiently target low-copy-number sequences via a complexity reduction method and have been successfully applied for genetic diversity studies in different species [18-21]. Moreover, DArTseq provides data at an affordable cost, especially in complex polyploid species such as wheat (https://www.diversityarrays.com), where it has been extensively used [20, 22, 23]. It is indeed the method employed by CIMMYT to build the most comprehensive genotype datasets for genetic resources in wheat (https:// seedsofdiscovery.org/about/genotyping-platform/).

High-throughput genotyping also provides essential information for the design of high-power GWAS, which enable the identification of agriculturally important genes and facilitate their transfer from wild or local germplasm into modern cultivars through marker-assisted selection and marker-assisted breeding and/or genomic selection. For GWAS analysis, the optimum diverse panel must be genotyped with a set of molecular markers covering as much of the genome of the species as possible [24], but the population structure needs to be investigated to avoid false associations between phenotypes and markers [25].

The Spanish wheat landraces conserved at the $\mathrm{Na}$ tional Plant Genetic Resources Center (CRF-INIA) and maintained in the national collection were collected in the first half of the twentieth century. Several studies have shown the great variability of the Spanish durum wheat accessions compared to other germplasm collections [26-29]. However, no genetic description of the bread wheat landraces has been reported, and the highthroughput genomic characterization of the durum wheat landraces remains to be fully realized. 
The aim of the present study was to characterize two collections of durum and bread wheat landraces from CRFINIA by using the DArTseq-GBS approach. The specific objectives of the present investigation were: (1) to assess the genomic diversity of a set of durum wheat accessions comprising 191 Spanish landraces and 23 reference varieties, (2) to assess the genomic diversity of a set of bread wheat accessions comprising 189 Spanish landraces and 29 reference varieties, and (3) to compare the genetic diversity of landraces and modern cultivars in both wheat species.

\section{Results}

\section{Wheat genotyping}

We characterized a set of 380 landraces and 52 reference varieties at genomic level (Additional file 1). The
DArTseq approach allowed us to detect approximately $100 \mathrm{~K}$ DArTs (presence/absence markers) and $50 \mathrm{~K}$ SNPs in each analyzed species.

In tetraploid durum wheat (214 accessions), a total of 98,983 DArTseq markers and 51,751 SNP markers were obtained (Additional files 2 and 3). When the markers were located in the T. turgidum reference genome, they were distributed throughout the genome (Table 1). According to the raw data, approximately $58 \%$ of the DArTs, and $37 \%$ of the SNPs were not located in the T. turgidum reference genome. After filtering to obtain highly informative markers, 38,700 DArTs and 9324 SNPs were selected for further analysis. In this set of markers, the percentage of located markers was similar to that from the raw data (66\% in SNPs and 45\% in DArTs). As shown in Table 1,

Table 1 Numbers of SNP and DArT markers identified in T. turgidum and T. aestivum accessions. The total numbers of markers before and after filtering, and their distribution within the genomes and chromosomes are presented. NA, no data available, as D genome is not present in T. turgidum

\begin{tabular}{|c|c|c|c|c|c|c|c|c|}
\hline & Triticum turgi & & & & Triticum aest & & & \\
\hline & Raw DARTs & $\begin{array}{l}\text { Filtered } \\
\text { DARTs }\end{array}$ & Raw SNPs & $\begin{array}{l}\text { Filtered } \\
\text { SNPs }\end{array}$ & Raw DARTs & $\begin{array}{l}\text { Filtered } \\
\text { DARTs }\end{array}$ & Raw SNPs & $\begin{array}{l}\text { Filtered } \\
\text { SNPS } \\
\end{array}$ \\
\hline Total & 98,983 & 38,700 & 51,751 & 9324 & 130,899 & 44,241 & 58,660 & 8238 \\
\hline Located & 41,429 & 17,442 & 32,811 & 6192 & 46,665 & 16,090 & 34,497 & 4738 \\
\hline Not located & 57,554 & 21,258 & 18,940 & 3132 & 84,234 & 28,151 & 24,163 & 3500 \\
\hline Genome A & 19,307 & 7907 & 15,719 & 2957 & 16,127 & 5957 & 12,762 & 1958 \\
\hline Genome B & 22,122 & 9535 & 17,092 & 3235 & 17,754 & 7000 & 13,636 & 1963 \\
\hline Genome D & NA & NA & NA & NA & 12,784 & 3133 & 8099 & 817 \\
\hline $1 \mathrm{~A}$ & 2047 & 863 & 1758 & 378 & 1841 & 723 & 1594 & 285 \\
\hline $1 B$ & 2972 & 1311 & 2341 & 505 & 2431 & 952 & 1888 & 278 \\
\hline $1 \mathrm{D}$ & NA & NA & NA & NA & 1797 & 384 & 1046 & 101 \\
\hline $2 \mathrm{~A}$ & 3079 & 1173 & 2581 & 519 & 2549 & 891 & 2072 & 302 \\
\hline $2 B$ & 4017 & 1661 & 3117 & 553 & 3188 & 1272 & 2500 & 345 \\
\hline $2 \mathrm{D}$ & NA & NA & NA & NA & 2501 & 773 & 1627 & 156 \\
\hline $3 \mathrm{~A}$ & 2757 & 1057 & 2252 & 409 & 2258 & 687 & 1923 & 316 \\
\hline $3 B$ & 3604 & 1570 & 2795 & 527 & 2763 & 1076 & 2256 & 331 \\
\hline $3 \mathrm{D}$ & NA & NA & NA & NA & 1877 & 406 & 1279 & 106 \\
\hline $4 \mathrm{~A}$ & 2587 & 1050 & 1805 & 295 & 2233 & 877 & 1453 & 167 \\
\hline $4 \mathrm{~B}$ & 1763 & 743 & 1328 & 295 & 1492 & 491 & 1028 & 145 \\
\hline $4 \mathrm{D}$ & NA & NA & NA & NA & 1033 & 170 & 515 & 71 \\
\hline $5 \mathrm{~A}$ & 2603 & 998 & 2224 & 486 & 2135 & 701 & 1749 & 330 \\
\hline $5 B$ & 3054 & 1197 & 2332 & 462 & 2572 & 1007 & 1948 & 299 \\
\hline $5 \mathrm{D}$ & NA & NA & NA & NA & 1731 & 383 & 1068 & 119 \\
\hline $6 \mathrm{~A}$ & 2364 & 1027 & 1819 & 306 & 1909 & 777 & 1385 & 203 \\
\hline $6 \mathrm{~B}$ & 3360 & 1541 & 2567 & 411 & 2467 & 1027 & 1970 & 283 \\
\hline $6 \mathrm{D}$ & NA & NA & NA & NA & 1536 & 432 & 1013 & 118 \\
\hline $7 \mathrm{~A}$ & 3870 & 1739 & 3280 & 564 & 3202 & 1301 & 2586 & 355 \\
\hline $7 \mathrm{~B}$ & 3352 & 1512 & 2612 & 482 & 2841 & 1175 & 2046 & 282 \\
\hline 7D & NA & NA & NA & NA & 2309 & 585 & 1551 & 146 \\
\hline
\end{tabular}


the filters applied did not affect the marker distribution within the genome. The A and B genomes presented a comparable number of markers, both before and after filtering. Chromosome 4B exhibited the lowest density of both types of markers.

For hexaploid bread wheat (218 accessions), a slightly higher number of markers, including 130,899 DArTseq markers and 58,660 SNPs, was generated (Additional files 4 and 5). As in durum wheat, the markers were detected throughout the whole genome; around 64\% of raw DArTs and $41 \%$ of raw SNPs were not located in the bread wheat reference genome, a percentage similar to that of the durum wheat (Table 1). After filtering, 44,241 DArTs and 8238 SNPs were selected for further analysis. In this set of markers, the percentage of located markers was similar to the percentage obtained in the raw data (36\% in DArTs and $57 \%$ in SNPs). The D genome presented a reduced amount of markers compared to A and B genomes. Regarding these latter, chromosome $4 \mathrm{~B}$ exhibited again the lowest density of both types of markers.

The marker distribution along the chromosomes was comparable in bread and durum wheat for all the A and B genome chromosomes. In general, a higher density of markers was found at both chromosome ends, as illustrated for chromosome 2A in Fig. 1. The same pattern was observed for the bread wheat $\mathrm{D}$ genome chromosomes.

In both species, the distribution of PIC (polymorphic index content) values for the DArT and SNP data was asymmetrical and skewed towards the lower values (Fig. 2).
In durum wheat, $82 \%$ of the DArTs and $75 \%$ of the SNP markers showed a PIC value $>0.2$. In bread wheat, the corresponding values were 76 and $70 \%$ for DArTs and SNPs, respectively. For both species and types of markers, the average PIC values were between 0.30 and 0.35 .

\section{Genetic structure of the durum wheat collection} fastSTRUCTURE runs with 38,700 DArT markers divided the tetraploid wheat landraces into seven populations (K=7) (Fig. 3a). All but one (BGE021775) of the 14 accessions belonging to subsp. dicoccon were grouped in Pop5, and all 37 of the subsp. turgidum accessions were clustered in Pop3. The landraces in both populations came mostly from the north of Spain (Fig. 3b). All of the 140 subsp. durum landraces except for one (BGE013103), which was classified into Pop3, were distributed among five populations (Pop1, Pop2, Pop4, Pop6 and Pop7), containing between 10 and 80 accessions (Additional file 1). Pop6 exhibited the highest number of accessions, showed the greatest degree of admixture and was the population with the most diverse eco-geographical origin (Fig. 3). However, some subsp. durum populations showed a narrower geographic distribution (Additional file 1). That is, the landraces in Pop1 originated mostly from eastern Spain, whereas those in Pop2 came from the south-western provinces. Pop4 included landraces from the South and East of Spain, and from the Canary Islands.

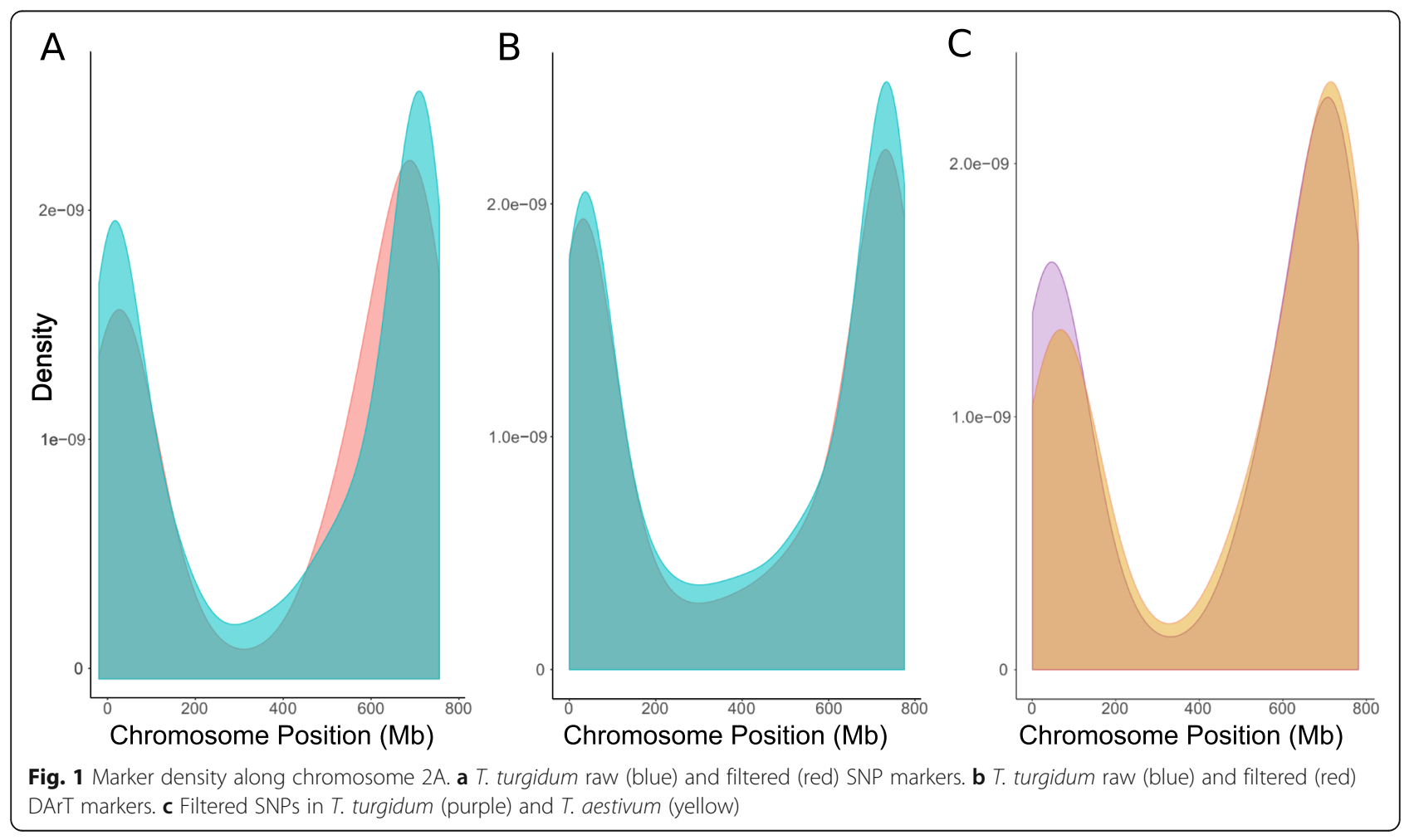



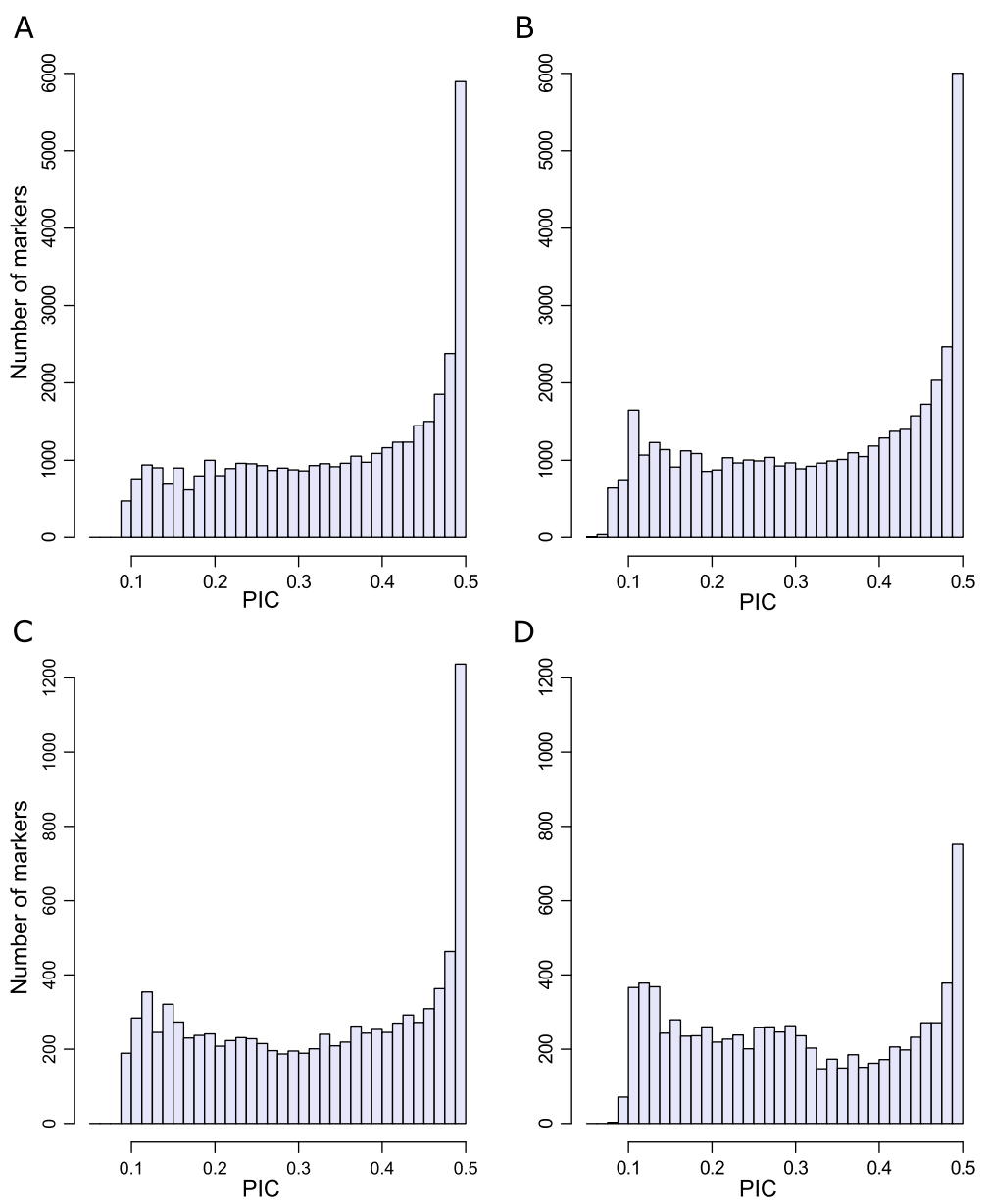

D

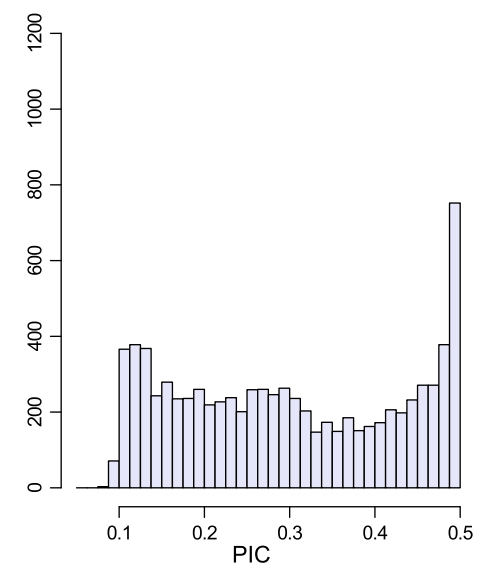

Fig. 2 Average PIC distribution in filtered markers. a T. turgidum DArTs. b T. aestivum DArTs. c T. turgidum SNPs. d T. aestivum SNPs

Genetic diversity parameters were calculated for the fastSTRUCTURE populations based on the SNP data (Table 2). The population with the highest genetic diversity value (Hs, Nei's diversity index) was Pop6 (0.272), and the population with the lowest value was Pop2 (0.048). For the whole landrace collection, the $\mathrm{D}_{\text {est }}$ (Population differentiation index) value, a measure of population differentiation in collections with several populations, was 0.22 . The $\mathrm{F}_{\mathrm{ST}}$ values, which are related to genetic differentiation between populations, ranged from 0.743 (Pop2 vs Pop5) to 0.226 (Pop1 vs Pop6). Pop6 showed the least genetic differentiation from the rest of the populations, including those of subsp. turgidum (Pop3) and dicoccon (Pop5) (Table 2). When the diversity between the three subspecies was estimated, regardless of the structured populations, the dicoccon and durum landraces showed the highest value of genetic differentiation between the subspecies $\left(\mathrm{F}_{\mathrm{ST}}=0.42\right)$ whereas subsp. turgidum showed lower values compared to either durum and dicoccon $\left(\mathrm{F}_{\mathrm{ST}}=0.31\right.$ and 0.38 , respectively).

When we analyzed the distribution of Hs values across the genome, we detected some genomic diversity patterns that were population- specific (Additional file 6). For example, Pop2 and Pop7 presented a region of low diversity in the central part of chromosome $2 \mathrm{~A}$, while for chromosome $2 \mathrm{~B}$ we only detected a region of low diversity in Pop5. On the other hand, a similar analysis contrasting the Hs values across the genome in the three durum wheat subspecies showed some common low diversity regions in turgidum and dicoccon (e.g., chromosomes 1A and $2 \mathrm{~A}$ ), while durum showed higher diversity values across the genome (Additional file 7).

We also explored the genomic structure of the durum wheat collection, including the landraces and reference varieties, through a principal coordinate analysis ( $\mathrm{PCoA})$ based on the 9324 filtered SNP markers. The first two principal coordinates explained $21 \%$ of the total variation. Three discrete groups corresponding to the three subspecies could be clearly identified (Fig. 4a). This was in agreement with the results obtained with fastSTRUCTURE where the three subspecies were grouped into different populations. A fourth group corresponding to the reference varieties also appeared to be clearly separated from the subsp. durum landraces. The subsp. durum 


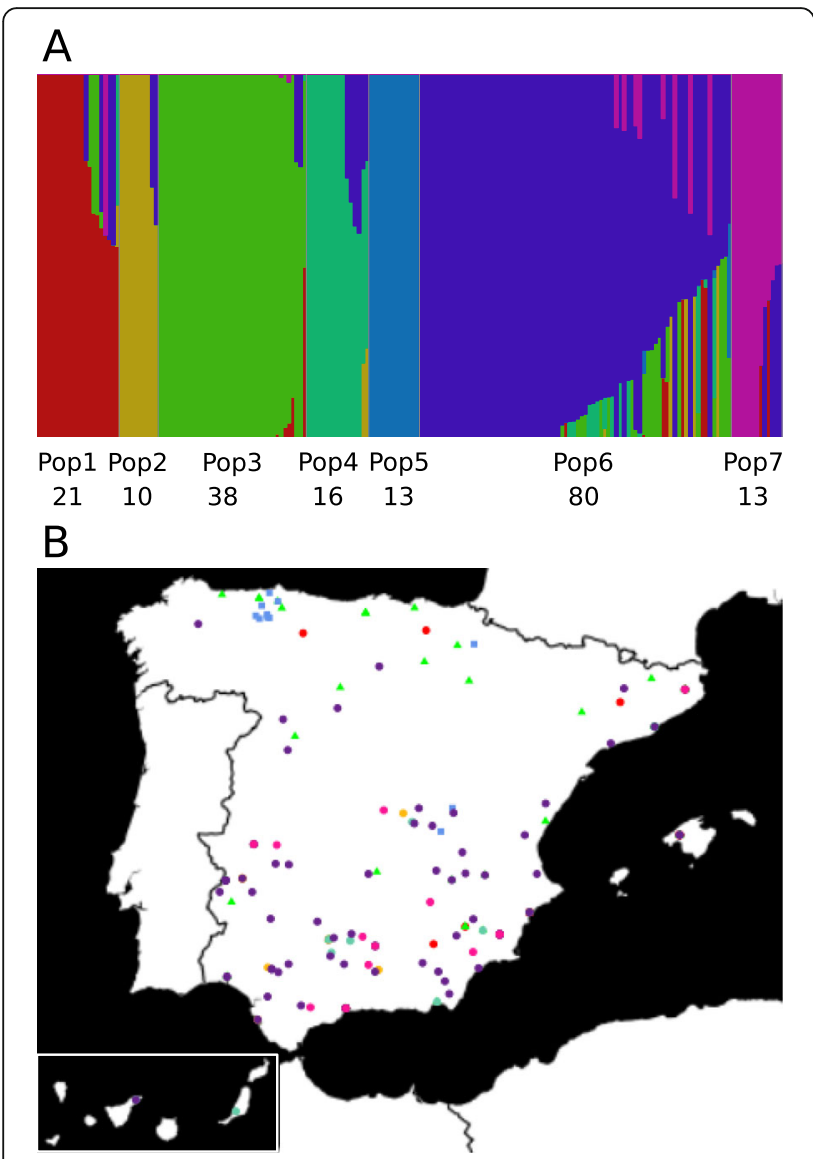

Fig. 3 a T. turgidum STRUCTURE plot based on DArT markers. The number below the Pop indicates the number of accessions clustered in each population. $\mathbf{b}$ Collection sites of the different T. turgidum accessions, colored according to their STRUCTURE population assignment. When GPS coordinate data were not available, the coordinates of the capital of the province of origin were used. T. turgidum subsp. durum landraces are shown with circles, subsp. dicoccon with squares and subsp. turgidum with triangles

accessions were differentiated from the others by PCo1, but the difference between turgidum and dicoccon was due to PCo2, demonstrating that different sets of markers are responsible of the genetic divergence among subspecies, as detected in the Hs analysis. Some landraces of

Table 2 Genetic diversity within populations $(\mathrm{Hs})$ and $\mathrm{F}_{\text {ST }}$ values between populations of $T$. turgidum landraces assessed with SNPS

\begin{tabular}{llllllll}
\hline Hs & 0.186 & 0.048 & 0.253 & 0.089 & 0.169 & 0.272 & 0.104 \\
FST $_{\text {Pop7 }}$ & Pop1 & Pop2 & Pop3 & Pop4 & Pop5 & Pop6 & Pop7 \\
Pop6 & 0.476 & 0.709 & 0.474 & 0.653 & 0.692 & 0.238 & - \\
Pop5 & 0.573 & 0.297 & 0.311 & 0.264 & 0.452 & & \\
Pop4 & 0.546 & 0.730 & 0.532 & & & & \\
Pop3 & 0.371 & 0.526 & & & & & \\
Pop2 & 0.575 & & & & & & \\
\hline
\end{tabular}

The different populations names (Pop) are highlighted in bold subsp. durum were located close to subsp. dicoccon and turgidum. These landraces were from Pop6 and some of them (e.g., BGE019290) come from the North of Spain (Additional file 1).

We further investigated the allelic variability of a functional marker involved in wheat adaptability, the vernalization gene $V r n-A 1$, in relation to the population structure. Three different alleles were identified in the collection: the winter-type allele $v r n-A 1$, and two alleles related to the spring growth habit, Vrn-A1b and VrnA1c. The representation of allelic variation in the PCoA showed that most of the accessions carrying the wintertype allele, vrn-A1, were grouped together and corresponded to dicoccon accessions (Fig. 4a). Most of the reference cultivars and subsp. durum accessions carried the $V r n-A 1 c$ allele, and almost all of the subsp. turgidum accessions carried the $V r n-A 1 b$ allele. When analyzed within the population structure, all but one durum accession from Pop2, Pop7, and Pop1 presented the VrnA1c allele, which was also identified in the $80 \%$ of the durum wheat landraces clustered in Pop 6. In Pop3 and Pop4, the most frequent allele was $V r n-A 1 b$. According to passport data (see Additional file 1), the accessions with the winter-type allele $v r n-A 1$ came mostly from the North of Spain.

Allelic variation was also studied for the HMW-GS (High Molecular Weight Glutenin Subunits) loci Glu-A1 and $G l u-B 1$, which are related to wheat rheological properties, but no relationship with the population structure could be observed (data not shown).

As the subspecies was the main discriminant factor in the global PCoA, we decided to perform the analysis excluding the turgidum and dicoccon accessions to gain insight into the variability within subsp. durum (Fig. 4b). The populations identified in the previous analysis with DArTs (Fig. 3a) were similarly grouped in the SNPbased PCoA, with Pop6 again being the population showing the greatest dispersion due to its higher intrapopulation variability (Fig. 3a). The only durum accession clustered in Pop3 (BGE013103) appeared to be located close to the Pop1 landraces in this case (Fig. 4b). This local variety can be identified in Fig. 3a at the edge of Pop3, showing admixture with Pop1, which suggests that it could present a hybrid genotype between durum and turgidum.

Pop1, Pop2, and Pop7 were the durum populations that were most differentiated from the reference set. On the other hand, Pop4 was closest to the reference group. This population included old local varieties such as 'Ledesma' and 'Lebrija', obtained from crosses between 'Senatore Capelli' and Spanish landraces. One landrace from Pop6 of subsp. durum (BGE026954) was grouped together with the reference varieties. This accession, collected at the end of the 1990, is characterized by early- 


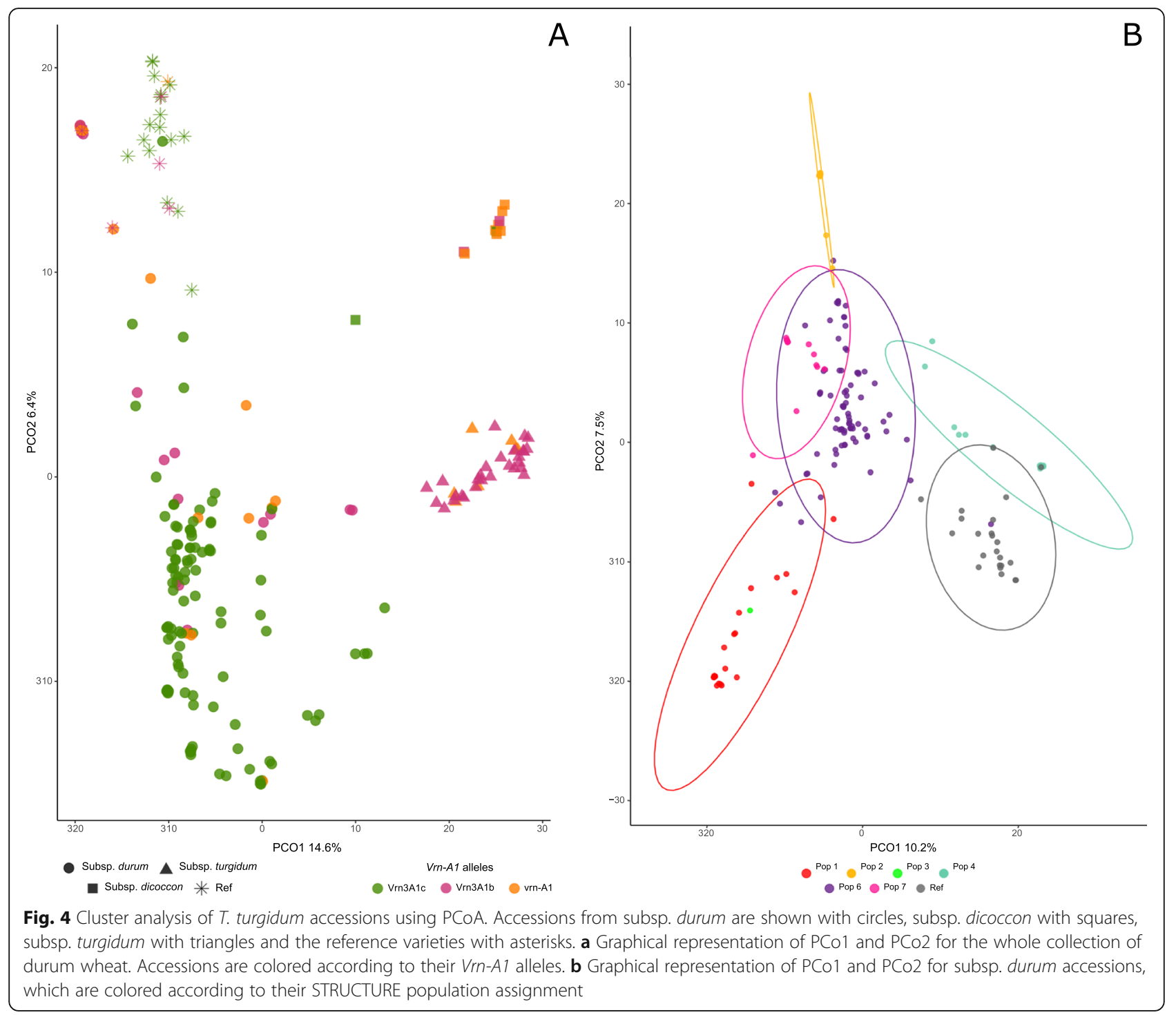

maturity and short plants [22], which suggests that it is probably not a true landrace.

\section{Genetic structure of the bread wheat collection}

fastSTRUCTURE runs with 44,241 DArT markers divided the hexaploid wheat landrace accessions into four populations $(K=4)$. Compared to durum wheat landraces, a higher level of admixture was detected in the bread wheat populations, especially within Pop2, which was the largest population, containing 112 accessions (Fig. 5a, Additional file 1). The landraces from Pop1 came from central Spain, and the landraces from Pop4 came from the west, including the Canary Islands. Pop2 and Pop3 showed more diverse eco-geographical origins (Fig. 5b, Additional file 1).

As shown in Table 3, the population with the highest Hs was Pop2 (0.277), and the population with the lowest value was Pop3 $(0.101)$. In the whole landrace collection, the $D_{\text {est }}$ value was 0.17 , which was lower than the differentiation found in the durum collection (0.22). The $\mathrm{F}_{\mathrm{ST}}$ values between populations ranged from 0.169 (Pop1 vs Pop2) to 0.573 (Pop3 vs Pop4). According to the $\mathrm{F}_{\mathrm{ST}}$ values, Pop4 was the most differentiated population (Table 3). Regarding the Hs distribution across the genome, we detected some low-diversity regions specific to certain populations (Additional file 8). For instance, Pop3 and Pop4 showed low-diversity regions on chromosomes $1 \mathrm{~A}$ and $7 \mathrm{~A}$, while Pop1 and Pop3 showed low diversity on chromosomes 3A and $2 \mathrm{~B}$. This suggests that different genomic regions are responsible for the divergence among populations.

The relationships among the bread wheat accessions were also assessed by PCoA, based on 8238 SNPs in the whole bread wheat collection. The total amount of genetic variation explained by the first two principal coordinates was $19.2 \%$. The first two coordinates clearly separated the Pop4 (by PCo1), which formed the most distant group, 


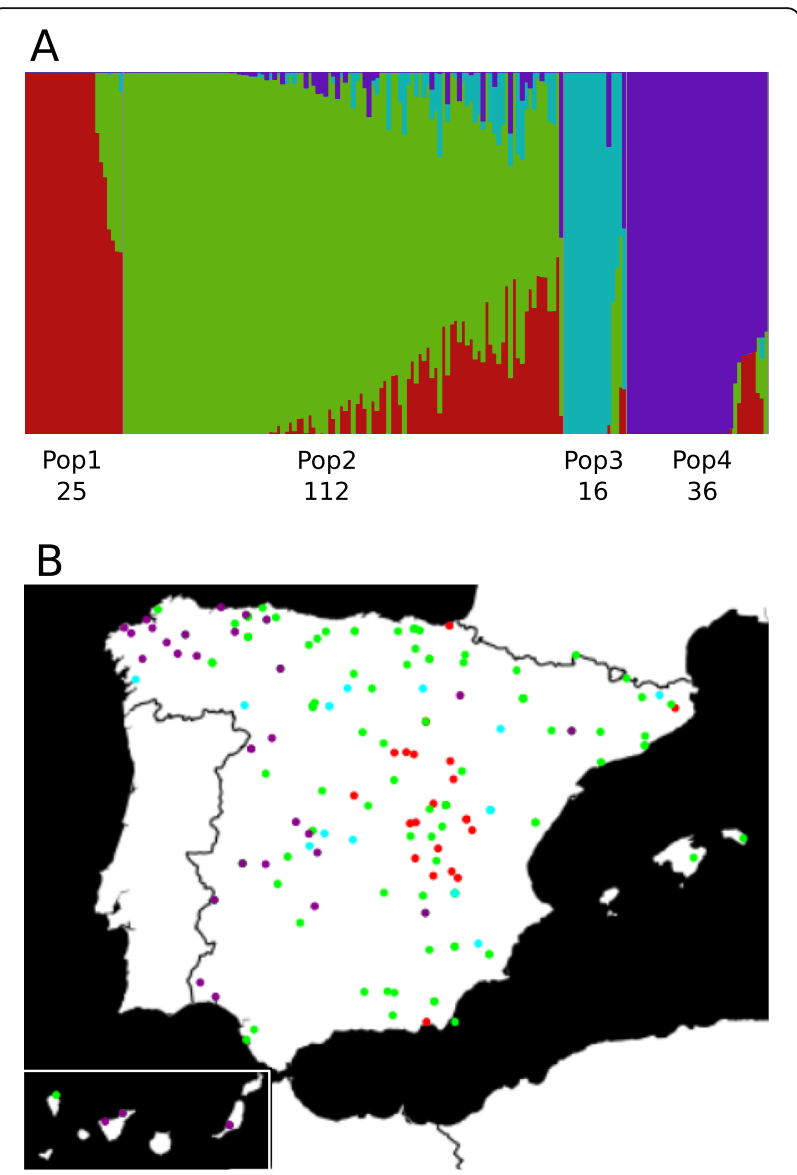

Fig. 5 a T. aestivum STRUCTURE plot based on DArT markers. The number below the Pop indicates the number of accessions clustered in each population. $\mathbf{b}$ Collection sites of the different $T$. aestivum accessions, colored by their STRUCTURE population assignment. When GPS coordinate data were not available, the coordinate of the capital of the province of origin were used

from the other three populations, which appeared to be distributed along PCo2 (Fig. 6a). Some degree of overlap was shown between Pop2, distributed along PCo2, and both Pop1 and Pop3, located at the upper extreme of PCo2. These results are in agreement with the higher degree of admixture in Pop2 revealed by fastSTRUCTURE analysis (Fig. 5a). The reference varieties were located within a quite limited space but overlapped with some Pop2 landraces.

Table 3 Genetic diversity within populations $(\mathrm{Hs})$ and $\mathrm{F}_{\mathrm{ST}}$ values between populations of T. aestivum landraces assessed with SNPS

\begin{tabular}{lllll}
\hline Hs & 0.176 & 0.277 & 0.101 & 0.188 \\
F $_{\text {ST }}$ & Pop1 & Pop2 & Pop3 & Pop4 \\
Pop4 & 0.506 & 0.346 & 0.573 & - \\
Pop3 & 0.483 & 0.265 & & \\
Pop2 & 0.169 & & & \\
\hline
\end{tabular}

The different populations names (Pop) are highlighted in bold
As in durum wheat, we investigated the allelic variability of the Vrn-A1 gene in relation to the bread wheat population structure. Three different alleles were identified in the collection: the winter-type allele vrn-A1 and two alleles that are generally related to a spring growth habit, Vrn-Ala and Vrn-A1b. The accessions from Pop4 were characterized by almost exclusively presenting the $V r n-A 1 b$ allele. The accessions presenting the other two alleles could be differentiated along the $\mathrm{PCo} 2$ axis, whose upper portion corresponded to spring-type landraces, whereas the reference varieties and winter-type landraces were included in the lower portion (Fig. 6a).

The representation of Glu-B1 alleles specific to Iberian landraces in the PCoA showed that the accessions that carried the Glu-B1f allele (HMW-GS $13+16$ ) were clustered on the right side of the PCoA and corresponded to most of the Pop4 samples. Again, an interesting tendency could be observed along the PCo2 axis: accessions with the Glu-B1e allele (HMW-GS 20x + 20y) appeared to be grouped in the upper portion, while the lower portion corresponded to accessions with Glu-B1u or Glu-B1al alleles (HMW-GS $7+8$ or $7 \mathrm{OE}+8$ ) (Fig. 6b). The allelic variation was also studied for HMW-GS loci Glu-A1 and Glu-D1, but no relationship with the population structure could be observed (data not shown).

The overlap between the landraces and reference varieties was more remarkable in bread wheat than in durum wheat. In fact, the reference varieties fully overlapped with the Pop2 accessions. Some of the landraces located closer to the reference varieties were collected in the 1990s (e.g., BGE025410), and according to their early flowering and lower height phenotypes (http://webx.inia. es/web_coleccionescrf/CaracterizacionCRFeng.asp), they may not be real landraces.

\section{Divergence between landraces and reference varieties}

As noted above, PCoA showed clear genetic divergence between the landraces and reference varieties of durum wheat, whereas such divergence was not as evident in bread wheat, in which the landraces and reference varieties overlapped (Figs. 4 and 6). Regarding the overall genetic diversity, the landraces showed higher diversity than the reference varieties in both species (Table 4), with the difference being greater in durum wheat.

The divergence between the reference varieties and landraces varied among the different populations identified by fastSTRUCTURE. The durum wheat reference varieties showed the highest differentiation from the landraces in Pop5 (dicoccon) and Pop2 (durum), and the lowest differentiation from the durum landraces in Pop4 and Pop6 $\left(\mathrm{F}_{\mathrm{ST}}\right.$ values of $0.586,0.555,0.372$ and 0.214 , respectively). In bread wheat, the reference varieties showed the highest and lowest differentiation from the landraces in Pop4 and Pop2, respectively $\left(\mathrm{F}_{\mathrm{ST}}\right.$ values of 0.416 and 0.08 , respectively). 

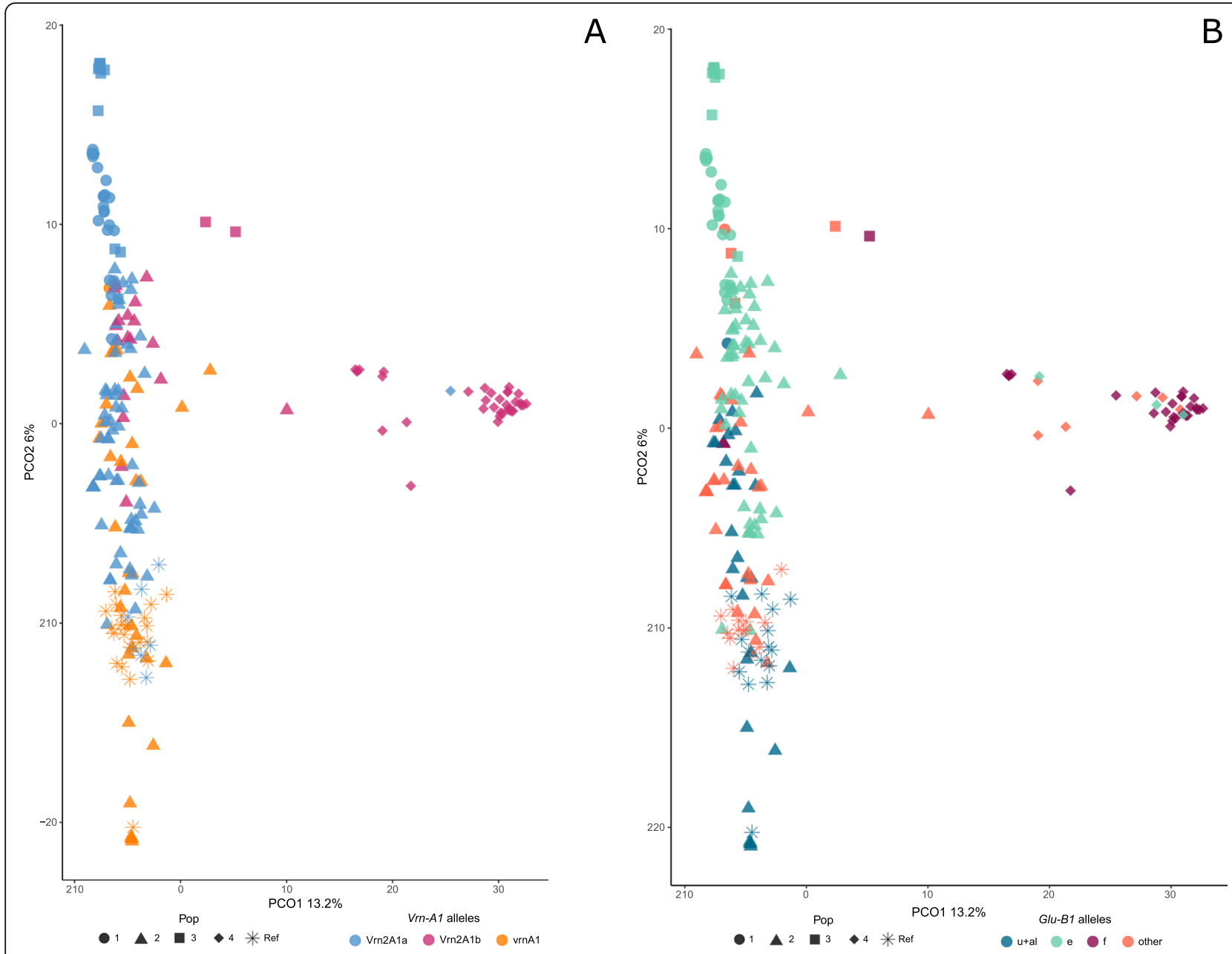

Fig. $\mathbf{6}$ Cluster analysis of T. aestivum accessions using PCOA. Accessions from STRUCTURE Pop1 are shown with circles, Pop2 with triangles, Pop3 with squares, Pop 4 with rhombi, and the reference varieties with asterisks. a Graphical representation of PCo1 and PCo2 for the whole collection of bread wheat. Accessions are colored according to their Vrn-A1 allele. $\mathbf{b}$ Accessions are colored according to their Glu-B1 allele

To analyze the degree of allele fixation in the reference varieties, we studied the presence of monomorphic markers. Approximately, $40 \%$ of the SNP markers were fixed in the durum wheat reference varieties, and the number of monomorphic markers (3791) was comparable to that found in subsp. dicoccon and turgidum (4079 and 2119 respectively) and much higher than that found in subsp. durum (478 fixed markers). In the bread wheat reference accessions, the number of fixed SNP markers was 1771 (21\%) clearly lower than the number obtained in durum wheat (Table 4).

Table 4 Overall genetic diversity (Hs) and number of monomorphic SNP markers in the set of reference varieties compared to landraces

\begin{tabular}{lcccccc}
\hline & \multicolumn{2}{c}{ Triticum turgidum } & & \multicolumn{2}{c}{ Triticum aestivum } \\
\cline { 2 - 3 } & Reference & Landraces & & Reference & Landraces \\
\hline Hs & 0.196 & 0.323 & & 0.250 & 0.300 \\
Monomorphic markers & 3791 & 24 & & 1771 & 2 \\
\hline
\end{tabular}

We also analyzed the Hs distribution across the genome in the landraces and reference varieties (Fig. 7). We called low-diversity regions in the reference varieties with respect to the landraces, as they might be regions fixed by breeding efforts. For this particular analysis, we employed a different set of markers, as described in Methods section, which include only SNPs located in the reference genomes. In durum wheat, we detected 20 of these genomic regions (Fig. 7a). Chromosomes 1A, $1 \mathrm{~B}, 2 \mathrm{~B}, 4 \mathrm{~B}, 5 \mathrm{~A}$ and $6 \mathrm{~B}$ did not present low-diversity regions, while the rest of chromosomes presented at least one fixed region. The largest wheat chromosome (3B) presented the greatest number of low diversity regions, with 5 regions spanning a total of $39 \mathrm{Mb}$. In turn, chromosome $2 \mathrm{~A}$ presented the widest region of low diversity $(37 \mathrm{Mb})$. In summary, the identified low-diversity regions spanned $218 \mathrm{MB}$. In bread wheat, a similar number [24] of lower-diversity regions were called (Fig. 7b). Interestingly, the $\mathrm{D}$ genome included only two low- 


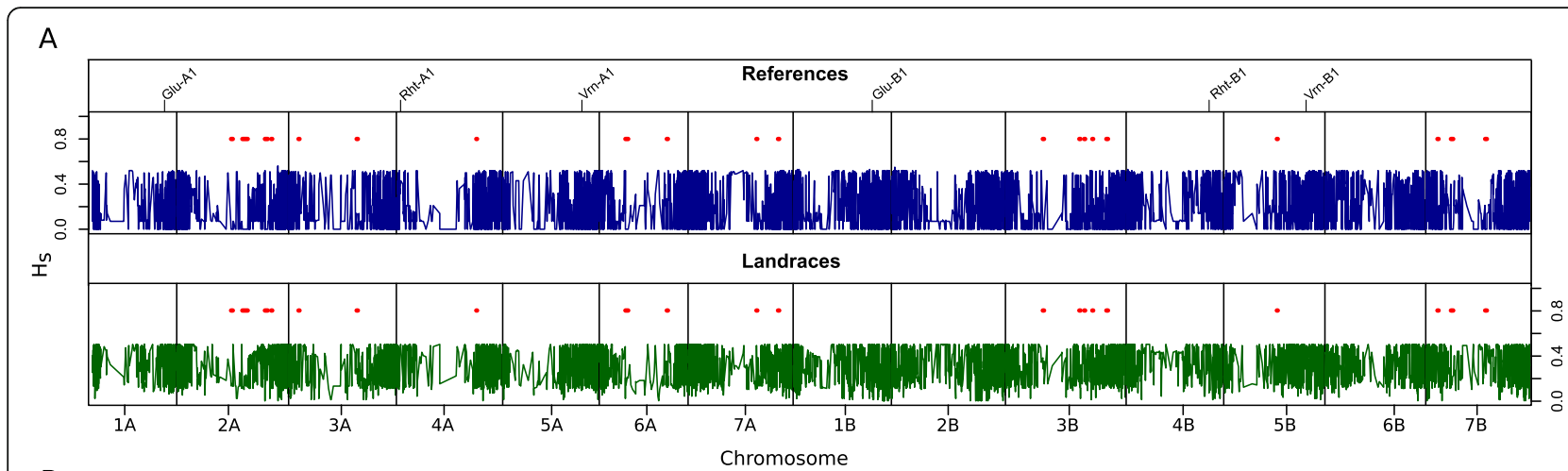

B

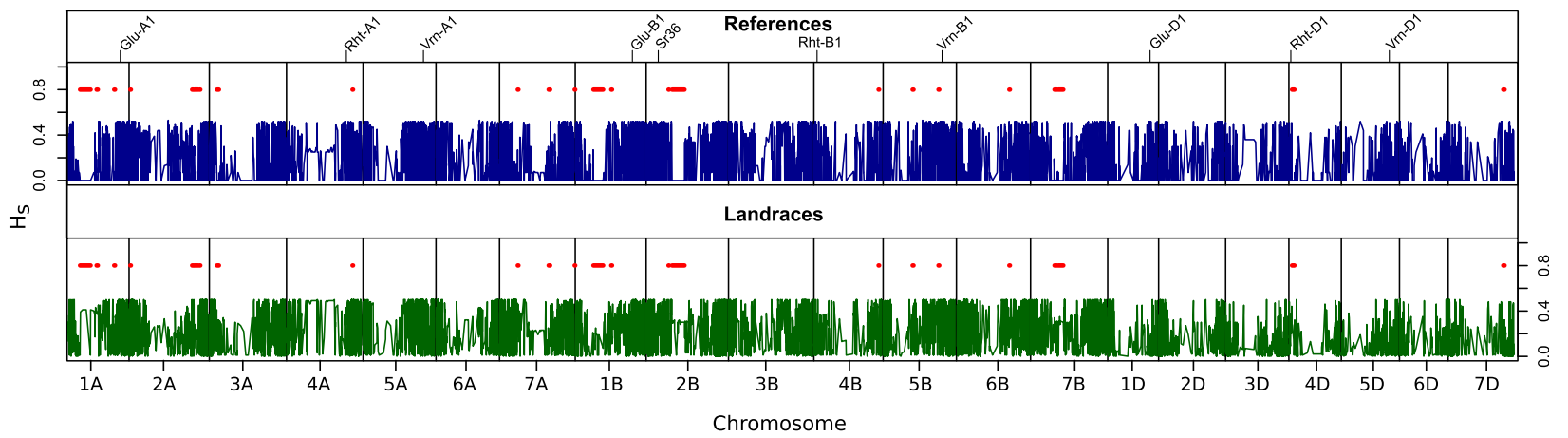

Fig. 7 Genetic diversity ( $\mathrm{Hs})$ distribution across the genome in the reference varieties and landraces. a T. durum. b T. aestivum. Fixed regions in the reference materials are indicated by red bars. The position of ten key genes in the genome is indicated

diversity regions. In the $\mathrm{A}$ genome, we detected 12 such regions located on chromosomes $1 \mathrm{~A}, 2 \mathrm{~A}, 3 \mathrm{~A}, 4 \mathrm{~A}$ and $7 \mathrm{~A}$, while in the $\mathrm{B}$ genome, we observed low-diversity regions on all the chromosomes except for $3 \mathrm{~B}$. The widest fixed region was located on chromosome $2 \mathrm{~B}$, spanning $121 \mathrm{Mb}$, and chromosome $2 \mathrm{~A}$ contained the greatest number of regions, with 4 regions. In bread wheat, the low-diversity regions spanned a total of $601 \mathrm{MB}$ and included the semidwarfing gene Rht-D1, a key gene introduced in wheat cultivars during the 20th that is located on chromosome 4D, and Vrn-B1, located on $5 \mathrm{~B}$ and related with growth habit.

\section{Discussion}

Modern bread and durum wheat varieties have resulted from breeding programs that have mainly been focused on achieving high yields in conventional agricultural systems. The unpredictable effects on crop performance under future climate scenarios and the increasing concern for the environmental consequences of crop management practices, which are commonly based on excessive irrigation and fertilizer application, are reorienting breeders' aims toward the development of new wheat cultivars that can maintain high yields under uncertain climatic conditions and in a more sustainable manner. For this purpose, genetic resources maintained in wheat genebanks, which have generally been underused, need to be thoroughly characterized so that the useful genetic variation that is present is transferred to modern elite gene pools. Several recent international initiatives are characterizing local wheat germplasm collections (www.seedsofdiscovery.org; www.divsek.org). However, Spanish landraces, which are locally adapted to a wide diversity of ecoclimatic conditions and mostly cultivated under rainfed low-input management systems, are absent or only represented by a small number of accessions in these studies. We decided to explore the genetic diversity of these valuable materials, by performing an analysis at the genomic level of 380 selected landraces representing the genetic variability of the wheat collection maintained at the Spanish Plant Genetic Resources Center, which is composed of more than 1600 accessions.

\section{Wheat high-throughput genotyping}

This is the first report of the high-throughput genotyping by GBS of Spanish wheat germplasm. The GBS method has the potential to provide robust in-depth genomic diversity estimates. Moreover, this approach may reveal new alleles that might present high value for prebreeding [30-32]. The DArTseq-GBS methodology has been successfully applied in wheat species, in which a standard GBS approach, requiring genome resequencing, is still challenging due to the extremely large complex genome [10]. 
In our study, $50 \mathrm{~K} \mathrm{SNP}$ and $100 \mathrm{~K}$ DArT markers were analyzed in each of the wheat species, from which we were able to select approximately $10 \mathrm{~K} \mathrm{SNP}$ and $40 \mathrm{~K}$ DArT high quality markers. The availability of the reference bread wheat genome [4] and durum wheat genome [5] allowed the marker location to be performed in both species. The results showed that markers were distributed throughout the genome, although $\mathrm{D}$ genome markers were markedly less abundant than A and B genome markers in bread wheat. Several previous studies have shown the reduced diversity of the wheat $\mathrm{D}$ genome, which has been explained by the close genetic distance between the Ae. tauschii parents involved in the formation of hexaploid wheat (e.g. [33, 34]). Among homoeologous sets, the group 4 chromosomes were the least covered, especially 4B and 4D. No satisfactory hypothesis has yet been proposed to explain the relative scarcity of markers consistently mapped on $4 \mathrm{~B}$ compared to $4 \mathrm{~A}[35,36]$, despite the latter being involved in several structural rearrangements in wheat [37].

The informativeness of the markers was assessed from their PIC values, and the distribution and average PIC value were found to be comparable to those previously reported in wheat $[20,38-41]$.

\section{Population structure of Spanish wheat landraces}

When a large germplasm collection is used for the identification of useful alleles or traits, knowledge of its genetic structure is highly recommended to optimize the search approach, which can then be focused on a smaller sample. The study of population structure is also important for genomic studies, as it is a mandatory prerequisite for successfully performing further GWAS analyses. In our case, since future GWAS analyses will be based on the high-quality SNPs identified herein, we decided to assess the structure with a different set of markers, DArTs. Population structure was assessed with the fastSTRUCTURE algorithm, which was developed by the authors of the classical STRUCTURE software but shows faster runs and provides comparable ancestry estimates and prediction accuracies [42]. In both species, the analysis of population structure was complemented with PCoA performed with the SNP dataset. As expected, the results were in close agreement, but some additional information about the subgroups and their relationship to phenotypic traits could be extracted.

\section{Durum wheat landraces}

The Spanish durum wheat (Triticum turgidum L.) landraces belong to three main interfertile subspecies (dicoccon, turgidum and durum). The subsp. dicoccon, also known as emmer wheat, is a hulled wheat that is only grown in the North of Spain and represents the feral situation of this crop. Subsp. durum is the most widely cultivated and well adapted to the dry-summer conditions of the South. Subsp. turgidum, which is less common and grown in colder areas than durum, mostly consists of winter wheat [43]. In a previous study, SSRs (Single Sequence Repeats) were used to assess the genetic structure of the collection of durum wheat landraces analyzed here and 9 populations were established. Some of the populations included more than one subspecies and several genotypes could not be classified into any population [27]. In the present work, we identified seven populations, all of which were composed of landraces from one subspecies with only two exceptions (Fig. 3). The discrepancies between this and the earlier work can be explained by the different types and numbers of markers employed for assessing the population structure in both studies (40 K DArTs vs 39 SSRs).

Analyses comprising other durum wheat materials have not been able to separate the durum and turgidum subspecies [44, 45]. However, we clearly differentiated the three subspecies. This demonstrates the analytical power of DArT and SNP markers for taxonomical identification and supports the classification of Mac Key [46, 47], with turgidum and durum as separate subtaxa. In our study, subsp. dicoccon was closer to turgidum than to durum (see $\mathrm{F}_{\mathrm{ST}}$ values, Table 2), indicating that the two subspecies share a common allele pool. As the two subspecies were grown in similar environmental conditions, this closeness might be due to similar selective pressures during local adaptation. The analysis also allowed the identification of accessions that could represent admixtures between subspecies, such as BGE021775, a dicoccon landrace located closer to durum, or BGE04564, a durum landrace grouped with the turgidum landraces. It has been reported that such admixture is not unusual in ancient local forms of durum wheat [47].

Vernalization genes are the main determinants of the growth habit (i.e., winter or spring) in temperate cereals, and by affecting the vegetative to reproductive transition, these genes are involved in the ability of wheat plants to adapt to a wide range of environments [48]. The evolution of spring-habit cultivars from winter-habit accessions played a key role in the postdomestication spread of wheat. However, studies on the major vernalization gene VRN1 have been mostly limited to hexaploid wheat species and very few reports from tetraploid species can be found in the literature $[48,49]$. None of the durum wheat accessions characterized here showed the $\mathrm{Vrn}-\mathrm{Ala}$ allele described in spring-habit hexaploid wheat varieties, which is in accordance with what has been found in other studies [50, 51]. All of the available data seem to indicate that this allele appeared during wheat evolution after the last polyploidization event. The $V r n-A 1 c$ allele has been described as the most frequent determinant of a spring habit in tetraploid wheat varieties $[50,52,53]$ but has been 
described as rare in emmer wheat varieties [44]. In our study, $78 \%$ of the durum accessions presented this allele, but almost all turgidum accessions (83\%) carried Vrn-A1b, and 7 out of the 11 dicoccon landraces characterized for $V r n-A 1$ carried the winter $v r n-A 1$ allele (Fig. 4). The presence of the spring-habit associated alleles $V r n-A 1 b$ and $V r n-A 1 c$ in the remaining four dicoccon accessions is remarkable. Emmer wheat varieties are traditionally cultivated in cool mountainous regions, where vernalization seems to be an unavoidable requirement. It may explain why few Spanish spring emmer wheat varieties have actually been described [43]. The spring type might have evolved from previous winter types as an adaptation to warmer conditions. Under the predicted climate change scenario, temperature warming may prevent the fulfilment of the requirements for vernalization in current temperate zones, thus having a negative global impact on winter wheat yields. The identification of genotypes with reduced vernalization requirements among germplasm adapted to cool zones could therefore be relevant for improving adaptability to changing eco-climatic conditions.

Within our collection, a restricted geographic distribution exists for the Spanish landraces belonging to the less represented subspecies dicoccon and, to some extent, for turgidum landraces. The clustering of these two groups of accessions, each in a single population, may reflect similar environmental conditions in their respective geographic origins. The landraces of subsp. durum, which were structured into five distinct populations, showed higher variability and greater complexity, including different phylogenetic groups [27]. The identified clusters seemed to be influenced by the accessions' origin relatively little, although some geographic areas were predominant in some of the populations. The gene flow between regions via germplasm exchanges and local preferences towards a given agrotype might be as significant as ecological conditions in determining the distribution of genetic diversity in this subspecies in Spain. The exchange of seeds by farmers has been noted as one of the likely explanations for the low or absent influence of geographic origin on the genetic structure of durum wheat landraces in Iran, the Central Fertile Crescent and Ethiopia $[20,54,55]$.

\section{Bread wheat landraces}

The great majority of the Spanish bread wheat landraces conserved at CRF-INIA belong to Triticum aestivum subsp. vulgare, and our bread wheat set was therefore composed exclusively of this subspecies. The population stratification of the bread wheat panel identified four groups of landraces with high divergence according to the obtained $\mathrm{F}_{\mathrm{ST}}$ values. This clustering reflected the geographic origin of the accessions better than in the subsp. durum. The genetic differentiation estimated with
$\mathrm{D}_{\text {est }}$ was lower in the bread landrace collection than in the whole durum wheat collection, in agreement with the lower level of stratification observed. Few studies have simultaneously addressed the variability of hexaploid and tetraploid wheat varieties but higher genetic diversity in durum than in bread wheat has been previously reported in landraces from other countries (e.g., [56]). Several studies support the occurrence of a limited number of independent crosses between the diploid and tetraploid progenitors of T. aestivum, where the resulting loss of diversity during the initial polyploidization step presumably caused a severe population bottleneck in hexaploid bread wheat $[33,57]$.

One of the four groups detected (Pop4) was clearly more genetically distant. This group included landraces from western Spain, where there is a prevalence of acidic or neutral soils [58]. Most of the accessions from this population show spring growth habit and carry the $f$ allele at the Glu-B1 locus. The Glu-B1f allele presents a low frequency in worldwide collections but has been previously described as being characteristic of Iberian landraces, which is also the case for the Glu-B1e allele [59]. The latter was predominant in Pop1 and Pop3, and was also present in some landraces of Pop2 that were closely grouped by PCoA. The Glu-B1e allele is related to poor rheological properties in bread wheat, but the $f$ allele has been associated with good dough quality [60]. The presence of this variant in a discrete group of more differentiated landraces supports their common origin.

In our study, the winter-type allele $v r n-A 1$ was the most common Vrn-A1 allele found in the T. aestivum reference cultivars (22 out of 29 varieties). However, the most frequent of these alleles within the bread wheat landraces was the $V r n-A 1 a$ allele, which was absent in the durum wheat. This Vrn-A1 allele, which results in complete insensitivity to vernalization, is recognized as the spring-habit allele with the greatest effect among all such alleles described [61]. Even if the growth habit shows just a limited impact on genetic differentiation, spring and winter bread wheat accessions are frequently separated by discriminant analysis of principal components [62, 63]. Two discrete groups regarding growth habit were not clearly defined in our PCoA, but the allelic variability of Vrn-A1 showed some relationship to population structure and a somewhat biased tendency along the second PCo axis (Fig. 6a). Regarding this matter, it must be kept in mind that the vernalization response is a complex process under polygenic control [64]. Vrn-A1 has been described as the main genotypic determinant of the vernalization requirements of temperate crops, but there are other genes, such as Vrn-B1 and Vrn-D1, whose allelic variability has not yet been characterized in these Spanish wheat landrace collections. 
This is the first time that the bread wheat resources maintained in the CRF-INIA Spanish national genebank have been characterized at the genetic level and compared to durum wheat accessions. This deep knowledge of their genetic structure represents the starting point for the development of a core collection of Spanish $T$. aestivum wheat varieties, which will allow the efficient management and use of this valuable gene pool.

\section{Relationship between landraces and modern cultivars}

In diversity studies, wheat landraces usually cluster in a separate group from elite cultivars [54, 55, 63, 65] but some degree of mixture has also been found [39, 62]. Concerning the durum wheat materials examined here, the great genetic divergence between the bulk of the landraces and the reference set is remarkable (Fig. 4a). Moreover, some of the durum landraces were located closer to turgidum and dicoccon accessions than to the reference varieties (which all belong to subsp. durum). However, high relatedness to the reference varieties was detected for a reduced group of durum landraces. This group included 'Caravaca' (BGE002869), a Spanish landrace used by CIMMYT in the development of some modern cultivars (see the Genetic Resources Information System for Wheat and Triticale of CIMMYT at http:// www.wheatpedigree.net/). It can also be noted that other studies have reported a close relationship between Spanish and North African landraces [39, 44] and that the reference set included two old cultivars that were commonly cultivated in Spain in the past ('Senatore Capelli' and 'Bidi-17'), both of which exhibit a North African origin. Nevertheless, our results supported little involvement of Spanish landraces in the development of the modern durum wheat varieties grown in Spain at present.

In bread wheat, the situation was quite different, and the mixing between the landraces and reference varieties was much higher, especially for some accessions in Pop2 (Fig. 6). It is likely that some of these accessions are not true local landraces but, rather, old improved cultivars that were wrongly classified. The clustering of the landraces and reference varieties could also indicate a pedigree relationship. Hence, it is possible that some of the landraces characterized in our study were among the unidentified "Mediterranean" local varieties utilized by the early breeders as starting material to develop pure lines that were further involved in cross-breeding (see http:// www.wheatpedigree.net/). Some other varieties such as 'Richela Blanca', 'Montnegre' or 'Ardito', are related to old Italian material [43, 66], which provides another feasible genealogical link between the sets of landraces and reference bread wheat materials analyzed.

The overall genetic diversity of the reference cultivars was much lower than that of the landraces in both species (Table 2; Figs. 4 and 6). Genomic regions showing patterns of variation that differ between landraces and varieties can aid in the identification of loci under selection during crop improvement, which will help to better target future breeding efforts [67]. Our analysis allowed the identification of several such genomic regions by studying the distribution of genetic diversity across the reference genomes (Fig. 7). The number of regions that have presumably been fixed by selective breeding was higher in bread wheat that in durum wheat. As expected, some of the chromosomes including fixed regions harbored genes related to agronomically important phenotypes, such as $R h t-D 1$, associated with dwarf phenotype, and Vrn-B1, associated with vernalization response, on bread wheat chromosomes $4 \mathrm{D}$ and $5 \mathrm{~B}$, respectively [68, 69]. In turn, the fixed region on bread wheat chromosome 1A may be related to the presence in this chromosome of major determinants of bread quality, such as the HMWGS encoding the Glu-1A locus. Coupling this analysis with future GWA studies will help to identify the traits underlying each of the fixed regions detected in this work.

\section{Conclusions}

The replacement of local landraces by high-yielding wheat varieties that began at the time of the Green Revolution has led to a loss of genetic variation in crop wheat varieties. This depletion has now encouraged the use of genetic resources in wheat breeding programs, but the genetic variability of these resources needs to be exhaustively characterized for their efficient use. The present study successfully used DArTseq technology for evaluating the diversity within and between two landrace collections of bread and durum wheat and for assessing the genetic relationships between each of these collections and a reference set of modern wheat cultivars. The study of genome-wide diversity provides a resource for the design of high-power GWAS experiments, which will help to achieve the overarching goal of improving wheat for cultivation in different environments, ecosystems and stress situations. The collections of Spanish landraces characterized in the present study were clearly clustered into different groups, representing different gene pools capable of providing different sources of genes for plant breeding. The investigated panel of genotypes showed an outstanding degree of diversity compared to the reference counterparts. It therefore clearly represents a strategic platform and a valuable genetic resource that must be further studied to ensure not only its efficient conservation and management but also its useful exploitation in breeding programs.

\section{Methods}

Plant material

The plant material analyzed in the present study comprised 432 selected accessions (detailed information is 
presented in Additional file 1). This sample included 191 durum and 189 bread wheat landraces and old local cultivars (hereafter referred to as landraces), representing different ecological and geographical areas of Spain $[27,70]$. Among the durum wheat landraces, 140, 37 and 14 landraces corresponded to the subspecies durum, turgidum and dicoccon, respectively, while all the bread wheat landraces belonged to the subspecies vulgare. All these accessions were homozygous lines derived from genebank accessions provided by CRF-INIA. Additionally, the study included a set of 23 improved varieties of durum wheat and 29 improved varieties of bread wheat (hereafter referred to as reference varieties), which comprised the cultivars most widely grown in Spain during the last 50 years plus some varieties widely used in wheat research, such as tetraploid 'Langdon' and hexaploid 'Chinese Spring'.

\section{DNA isolation and genotyping analysis}

For each accession, genomic DNA was isolated from the young leaves of a single plant using the CTAB method [71]. Samples were genotyped using DArTseq GBS technology at Diversity Arrays Technology Pvt., Ltd. (Canberra, Australia) for the durum wheat accessions and SAGA (Genetic Analysis Service for Agriculture, Mexico City, Mexico) for the bread wheat accessions [72, 73].

A complexity reduction method including two enzymes (PstI and HpaII) was used to create a genome representation of the set of samples. PstI-RE site specific adapter was tagged with 96 different barcodes enabling multiplexing a 96-well microtiter plate with equimolar amounts of amplification products in order to run within a single lane on Illumina HiSeq2500 instrument (Illumina Inc., San Diego, CA). The successful amplified fragments were sequenced up to 77 bases, generating approximately 500,000 unique reads per sample. Thereafter the FASTQ files (full reads of $77 \mathrm{bp}$ ) were quality filtered using a Phred quality score of 30, which represent a 90\% of base call accuracy for at least $50 \%$ of the bases. More stringent filtering was also performed on barcode sequences using a Phred quality score of 10 , which represent $99.9 \%$ of base call accuracy for at least $75 \%$ of the bases. A proprietary analytical pipeline developed by DArT P/L was used to generate allele calls for SNP and DArT markers.

After this process the genotyping services provided two different sets of markers. The DArT markers were scored as binary data $(0 / 1)$ indicating the presence or absence of a marker in each accession, and the SNP markers were scored as 0/1/2 indicating the presence of the reference allele in homozygosity, the alternative allele in homozygosity or a heterozygous genotype, respectively. The raw data are available upon request to the corresponding author. To locate the markers in the durum and bread wheat reference genomes, the markers sequences were subjected to BLAST searches against the currently available Triticum aestivum genome IWGSC Refseq v1.0 [4] for bread wheat markers and Triticum turgidum genome Svevo v1.0 [5] for durum wheat markers. A marker was located according to the following criteria BLAST E-value $<5 e-10$ and sequence identity $>90 \%$.

For comparison with the population structure based on GBS-DArTseq markers, we investigated the allelic variability of functional markers in the $V r n-A 1$ gene, one of the most determinant loci involved in the transition from vegetative to reproductive growth $[74,75]$. It has been described that carrying a dominant allele at the $V r n-A 1$ locus is sufficient to confer a spring growth habit [53]. Three alleles (Vrn-A1a, Vrn-A1b and Vrn-A1c) were characterized by PCR according to $[51,52,68]$ and following the protocols described at https://maswheat.ucdavis. edu/protocols/Vrn/index.htm.

Additionally, the panel of accessions was genotyped for Glu-1 homoeoloci. These complex loci encode the HMWGS, which are the major determinants of dough quality in wheat. For this purpose, endosperm proteins were extracted from single seeds and fractionated via sodium dodecyl sulfate polyacrylamide gel electrophoresis $(12 \%$ polyacrylamide gels) according to Payne et al. [76] HMW-GS allele classification was performed according to the Catalogue of Gene Symbols for Wheat 2013 [77].

\section{Data analysis}

Prior to any further analysis, the set of SNP and DART markers was filtered employing homemade $\mathrm{R}$ scripts [78], which are available upon request to the corresponding author. For DART markers we selected high quality markers following a step-by-step filtering strategy. First, when several markers presented the same allelic profile, all of the markers but the one with the least missing data were removed. Then, the markers that presented more than $10 \%$ missing data or were monomorphic (Minimum Allele Frequency, MAF < 0.05) were excluded.

For the SNP markers, prior to any filtering step we analyzed the presence of heterozygous genotypes. As we have previously described, genotyping was conducted on homozygous lines and thus we did not expect any heterozygous genotypes. When the genotypic values for a marker was only 0 and 2 , we considered the heterozygous calling [2] to be an error caused by the presence of the SNP marker flanking sequence in homoeologous genomes. In this case, the genotypes scored as 2 were recoded as 1 . The same procedure was followed when only genotypic values of 1 and 2 were present in a marker, but in those cases, genotypes scored as 2 were recoded as 0 . Finally, when the genotypic values for a marker included 0,1 and 2 we recoded the genotypes 
scored as 2 as missing data. After this analysis we selected high quality SNP markers following the filtering strategy described for the DART markers. First, when several markers presented the same allelic profile, all but the one with the less missing data were removed. Then, markers with more than $10 \%$ missing data or monomorphic (MAF < 0.05$)$ were excluded.

The genetic substructure within the durum and bread wheat landrace collections was investigated using the fastSTRUCTURE algorithm [42] and the DArT marker dataset (including all the available DArTs after filtering, located or not in the reference genomes). Default parameters and $\mathrm{K}$ values from 1 to 15 were tested. The appropriate number of components that explained the structure in the dataset was determined using the chooseK.py function [42]. The results for the identified optimal values of $\mathrm{K}$ were visualized using DISTRUCT [79]. Individual accessions were assigned to the population with the highest proportional membership.

The genetic similarity based on the SNP data within the full sets of accessions (landraces plus reference varieties) was analyzed by principal coordinates analysis (PCoA) using the gl.pcoa function from the dart $R$ package [80] (including all the available SNPs after filtering, located or not in the reference genomes).

The gene diversity $(\mathrm{Hs})$ within populations, landraces and reference varieties was calculated based on the SNP dataset according to [81] with the basic.stats function from the hierfstat $R$ package [82]. $D_{\text {est }}$, a measure of population differentiation in collections with several populations, was calculated as defined by [83] with this same function. The genetic differentiation between populations was analyzed by estimating the pairwise fixation index (Fst) according to [84] with the stamppFst function from $\mathrm{R}$ the StAMPP package [85] using the SNP dataset (including all the available SNPs after filtering, located or not in the reference genomes).

Fixed genomic regions in the reference varieties were identified by performing a scan of the Hs values along the different chromosomes. Hs was estimated as described previously [81]. However, for this analysis we obtained a new SNP dataset by avoiding the first filtering step, thus when several markers presented the same allelic profile we kept all of them and only filter out the markers that presented more than $10 \%$ missing data or were monomorphic (MAF < 0.05). Finally, for this particular analysis only markers with known location in the reference genomes were employed. A region was considered to be "fixed" when it contained at least 5 consecutive markers with an $\mathrm{Hs}$ equal to 0 in the reference varieties and at least 5 markers with an $\mathrm{Hs}>0.1$ in the landraces, and spanned more than $5 \mathrm{Mb}$.

\section{Supplementary information}

Supplementary information accompanies this paper at https://doi.org/10. 1186/s12864-020-6536-X.

Additional file 1. Excel file with the description of the accessions analyzed, passport data, population according to fastSTRUCTURE analysis, HMW-GS and VRN-A1 alleles. Sheet 1. Durum wheat. Sheet 2. Bread wheat. Sheet 3. Reference set.

Additional file 2. File with the T. durum accession raw DArT genotyping results.

Additional file 3. File with the T. durum accession raw SNP genotyping results.

Additional file 4. File with the T. aestivum accession raw DArT genotyping results.

Additional file $\mathbf{5}$. File with the T. aestivum accession raw SNP genotyping results.

Additional file 6. Figure showing the genetic diversity $(\mathrm{Hs})$ distribution across the $A$ and $B$ genomes in the different durum wheat populations identified with fastStructure.

Additional file 7. Figure showing the genetic diversity $(\mathrm{Hs})$ distribution across the $A$ and $B$ genomes in the different durum wheat subspecies.

Additional file 8. Figure showing the genetic diversity $(\mathrm{Hs})$ distribution across the $A, B$ and $D$ genomes in the different bread wheat populations identified with fastStructure.

\section{Abbreviations}

CIMMYT: Centro internacional de Mejoramiento de Maíz Y Trigo; CRFINIA: National Plant Genetic Resources Center; DArT: Diversity Array Technology; DArTseq: Diversity Array Technology sequence; $D_{\text {est }}$ : Jost's Population Differentiation index; $F_{\text {ST: }}$ Wright's Fixation index;

GBS: Genotyping By Sequencing; GWAS: Genome Wide Association Studies; HMW-GS: High Molecular Weight Glutenin Subunits; Hs: Nei's diversity index; MAF: Minimum Allele Frequency; MAS: Marker assisted selection; PCoA: Principal coordinates analysis; PIC: Polymorphic Information Content; SNP: Single nucleotide polymorphism; SSRs: Single Sequence Repeats

\section{Acknowledgments}

The authors are grateful to Dr. JM Carrillo for helpful comments during the preparation of the original and revised versions of the manuscript.

\section{Authors' contributions}

PG and MR: conceived and designed the study; EB, MLF, LP, MR and JFV: characterized the panel; MLF, LP, HPP and CS: performed the bioinformatics analyses; PG, LP and MR: valorized the results and wrote the manuscript; all authors have read and approved the final manuscript.

\section{Funding}

This work was supported by the Ministry of Economy, Industry and Competitiveness projects AGL2016-77149-C2-1P and RFP2015-00008-C04-01, the Comunidad Autónoma de Madrid project P2018/BAA-4330, and the Universidad Politécnica de Madrid project VJIDOCUPM18LPB. ML is a recipient of a predoctoral fellowship from the Programa Propio of the Universidad Politécnica de Madrid.

\section{Availability of data and materials}

Plant material and raw data are available upon request to the corresponding author.

Ethics approval and consent to participate Not applicable.

\section{Consent for publication}

Not applicable.

Competing interests

The authors declare that they have no competing interests. 


\section{Author details}

${ }^{1}$ Department of Biotechnology-Plant Biology, School of Agricultural, Food and Biosystems Engineering, Universidad Politécnica de Madrid, Madrid Spain. ${ }^{2}$ National Plant Genetic Resources Centre, National Institute for Agricultural and Food Research and Technology, Alcalá de Henares, Spain. ${ }^{3}$ Centro Internacional de Mejoramiento de Maíz y Trigo (CIMMYT), Texcoco, Mexico

Received: 30 April 2019 Accepted: 24 January 2020

Published online: 04 February 2020

\section{References}

1. Marcussen T, Sandve SR, Heier L, Spannagl M, Pfeifer M, Jakobsen KS, et al. Ancient hybridizations among the ancestral genomes of bread wheat. Science. 2014;345(6194):1250092.

2. Leng P, Lübberstedt T, Xu M. Genomics-assisted breeding-a revolutionary strategy for crop improvement. J Integr Agric. 2017;16(12):2674-85.

3. Mochida K, Yamazaki Y, Ogihara Y. Discrimination of homoeologous gene expression in hexaploid wheat by SNP analysis of contigs grouped from a large number of expressed sequence tags. Mol Gen Genomics. 2004;270(5): 371-7.

4. Appels R, Eversole K, Feuillet C, Keller B, Rogers J, Stein N, et al. Shifting the limits in wheat research and breeding using a fully annotated reference genome. Science. 2018;361(6403):eaar7191.

5. Maccaferri M, Harris NS, Twardziok SO, Pasam RK, Gundlach H, Spannagl M, et al. Durum wheat genome highlights past domestication signatures and future improvement targets. Nat Genet. 2019;51(5):885.

6. Rasheed A, Xia X. From markers to genome-based breeding in wheat. Theor Appl Genet. 2019;132(3):767-84.

7. Haudry A, Cenci A, Ravel C, Bataillon T, Brunel D, Poncet C, et al. Grinding up wheat: a massive loss of nucleotide diversity since domestication. Mol Biol Evol. 2007;24(7):1506-17.

8. Reif JC, Zhang P, Dreisigacker S, Warburton ML, van Ginkel M, Hoisington D, et al. Wheat genetic diversity trends during domestication and breeding. Theor Appl Genet. 2005;110(5):859-64.

9. Lopes MS, El-Basyoni I, Baenziger PS, Singh S, Royo C, Ozbek K, et al. Exploiting genetic diversity from landraces in wheat breeding for adaptation to climate change. J Exp Bot. 2015;66(12):3477-86.

10. Sehgal D, Vikram P, Sansaloni CP, Ortiz C, Pierre CS, Payne T, et al. Exploring and mobilizing the gene bank biodiversity for wheat improvement. PLoS One. 2015;10(7):e0132112.

11. Idrees $M$, Irshad M. Molecular markers in plants for analysis of genetic diversity: a review. Eur Acad Res. 2014;2(1):1513-40.

12. Govindaraj M, Vetriventhan M, Srinivasan M. Importance of genetic diversity assessment in crop plants and its recent advances: an overview of its analytical perspectives. Genet Res Int. 2015;2015:431487.

13. Khan MK, Pandey A, Choudhary S, Hakki EE, Akkaya MS, Thomas G. From RFLP to DArT: molecular tools for wheat (Triticum spp.) diversity analysis. Genet Resour Crop Evol. 2014;61(5):1001-32.

14. Wang S, Wong D, Forrest $\mathrm{K}$, Allen A, Chao S, Huang BE, et al. Characterization of polyploid wheat genomic diversity using a high-density 90000 single nucleotide polymorphism array. Plant Biotechnol J. 2014;12(6): 787-96

15. Elshire RJ, Glaubitz JC, Sun Q, Poland JA, Kawamoto K, Buckler ES, et al. A robust, simple genotyping-by-sequencing (GBS) approach for high diversity species. PLoS One. 2011;6(5):e19379.

16. Holtz Y, Ardisson M, Ranwez V, Besnard A, Leroy P, Poux G, et al. Genotyping by sequencing using specific allelic capture to build a highdensity genetic map of durum wheat. PLoS One. 2016;11(5):e0154609.

17. Cruz VMV, Kilian A, Dierig DA. Development of DArT marker platforms and genetic diversity assessment of the US collection of the new oilseed crop lesquerella and related species. PLoS One. 2013;8:e64062.

18. Valdisser PA, Pereira WJ, Almeida Filho JE, Müller BS, Coelho GR, de Menezes IP, et al. In-depth genome characterization of a Brazilian common bean core collection using DArTseq high-density SNP genotyping. BMC Genomics. 2017;18(1):423.

19. Yang X, Ren R, Ray R, Xu J, Li P, Zhang M, et al. Genetic diversity and population structure of core watermelon (Citrullus lanatus) genotypes using DArTseq-based SNPs. Plant Genet Resour. 2016;14(3):226-33.

20. Baloch FS, Alsaleh A, Shahid MQ, Çiftçi V, Sáenz de Miera L, Aasim M, et al. A whole genome DArTseq and SNP analysis for genetic diversity assessment in durum wheat from central fertile crescent. PloS One. 2017; 12(1):e0167821.

21. Robbana C, Kehel Z, Sansaloni C, Bassi F, Amri A. Genome-wide genetic diversity and population structure of tunisian durum wheat landraces based on DArTseq technology. Int J Mol Sci. 2019;20(6):1352.

22. Edet OU, Gorafi YS, Nasuda S, Tsujimoto H. DArTseq-based analysis of genomic relationships among species of tribe Triticeae. Sci Rep. 2018;8(1):1.

23. Rasheed A, Mujeeb-Kazi A, Ogbonnaya FC, He Z, Rajaram S. Wheat genetic resources in the post-genomics era: promise and challenges. Ann Bot. 2017; 121(4):603-16.

24. Korte A, Farlow A. The advantages and limitations of trait analysis with GWAS: a review. Plant Methods. 2013;9(1):29.

25. Zhao K, Aranzana MJ, Kim S, Lister C, Shindo C, Tang C, et al. An Arabidopsis example of association mapping in structured samples. PLoS Genet. 2007: 3(1):e4.

26. Pfluger LA, Martin LM, Alvarez JB. Variation in the HMW and LMW glutenin subunits from Spanish accessions of emmer wheat (Triticum turgidum ssp. dicoccum Schrank). Theor Appl Genet. 2001;102(5):767-72.

27. Ruiz M, Giraldo P, Royo C, Villegas D, Aranzana MJ, Carrillo JM. Diversity and genetic structure of a collection of Spanish durum wheat landraces. Crop Sci. 2012;52(5):2262-75.

28. Aguiriano E, Ruiz M, Fité R, Carrillo JM. Analysis of genetic variability in a sample of the durum wheat (Triticum durum Desf.) Spanish collection based on gliadin markers. Genet Resour Crop Evol. 2006;53(8):1543-52.

29. Moragues M, Moralejo M, Sorrells ME, Royo C. Dispersal of durum wheat [Triticum turgidum L. ssp. turgidum convar. durum (Desf.) Mackey] landraces across the Mediterranean basin assessed by AFLPs and microsatellites. Genet Resour Crop Evol. 2007;54(5):1133-44.

30. Kilian B, Graner A. NGS technologies for analyzing germplasm diversity in genebanks. Brief Funct Genomics. 2012;11(1):38-50.

31. Heslot N, Rutkoski J, Poland J, Jannink JL, Sorrells ME. Impact of marker ascertainment bias on genomic selection accuracy and estimates of genetic diversity. PLoS One. 2013;8(9):e74612.

32. Manickavelu A, Jighly A, Ban T. Molecular evaluation of orphan Afghan common wheat (Triticum aestivum L.) landraces collected by Dr. Kihara using single nucleotide polymorphic markers. BMC Plant Biol. 2014;14(1):320.

33. Dvorak J, Luo M, Yang Z, Zhang H. The structure of the Aegilops tauschii genepool and the evolution of hexaploid wheat. Theor Appl Genet. 1998; 97(4):657-70.

34. Lagudah ES, Appels R, Brown A, McNeil D. The molecular-genetic analysis of Triticum tauschii, the D-genome donor to hexaploid wheat. Genome. 1991:34(3):375-86

35. Qi LL, Echalier B, Chao S, Lazo GR, Butler GE, Anderson OD, et al. A chromosome bin map of 16,000 expressed sequence tag loci and distribution of genes among the three genomes of polyploid wheat. Genetics. 2004;168(2):701-12.

36. Miftahudin KR, Ma X, Mahmoud AA, Layton J, Milla MR, Chikmawati T, et al. Analysis of expressed sequence tag loci on wheat chromosome group 4. Genetics. 2004;168(2):651.

37. Devos KM, Dubcovsky J, Dvorak J, Chinoy CN, Gale MD. Structural evolution of wheat chromosomes $4 \mathrm{~A}, 5 \mathrm{~A}$, and $7 \mathrm{~B}$ and its impact on recombination. Theor Appl Genet. 1995:91(2):282-8.

38. Cubizolles N, Rey E, Choulet F, Rimbert H, Laugier C, Balfourier F, et al. Exploiting the repetitive fraction of the wheat genome for high-throughput single-nucleotide polymorphism discovery and genotyping. Plant Genome. 2016;9(1):1-11.

39. Kabbaj H, Sall AT, Al-Abdallat A, Geleta M, Amri A, Filali-Maltouf A, et al. Genetic diversity within a global panel of durum wheat (Triticum durum) landraces and modern germplasm reveals the history of alleles exchange. Front Plant Sci. 2017:8:1277.

40. Rimbert H, Darrier B, Navarro J, Kitt J, Choulet F, Leveugle M, et al. High throughput SNP discovery and genotyping in hexaploid wheat. PLOS One. 2018:13(1):e0186329.

41. Novoselovic D, Bentley AR, Simek R, Dvojkovic K, Sorrells ME, Gosman N, et al. Characterizing Croatian wheat germplasm diversity and structure in a European context by DArT markers. Front Plant Sci. 2016;7:184.

42. Raj A, Stephens M, Pritchard JK. Variational inference of population structure in large SNP datasets. Genetics. 2014;197:573-89.

43. Gadea M. Trigos españoles. Madrid: Instituto Nacional de Investigaciones Agronómicas; 1954 
44. Oliveira HR, Campana MG, Jones H, Hunt HV, Leigh F, Redhouse DI, et al. Tetraploid wheat landraces in the Mediterranean basin: taxonomy, evolution and genetic diversity. PLoS One. 2012;7(5):e37063.

45. Sahri A, Chentoufi L, Arbaoui M, Ardisson M, Belqadi L, Birouk A, et al. Towards a comprehensive characterization of durum wheat landraces in Moroccan traditional agrosystems: analysing genetic diversity in the light of geography, farmers' taxonomy and tetraploid wheat domestication history. BMC Evo Biol. 2014;14(1):264.

46. Mac Key J. Wheat: its concept. evolution and taxonomy. In: Royo C et al. (eds) Durum wheat breeding. Current approaches and future strategies. New York: Haworth Press. 2005;1:3-61.

47. Mac KJ. Species relationship in Triticum. Hereditas. 1966;2:237-76.

48. Basualdo J, Díaz ML, Cuppari S, Cardone S, Soresi D, Camargo GP, et al. Allelic variation and differential expression of VRN-A1 in durum wheat genotypes varying in the vernalization response. Plant Breed. 2015;134(5): 520-8.

49. Konopatskaia I, Vavilova V, Kondratenko EY, Blinov A, Goncharov NP. VRN1 genes variability in tetraploid wheat species with a spring growth habit. BMC Plant Biol. 2016;16(3):244.

50. Yan L, Loukoianov A, Blechl A, Tranquilli G, Ramakrishna W, SanMiguel P, et al. The wheat VRN2 gene is a flowering repressor down-regulated by vernalization. Science. 2004;303(5664):1640-4.

51. Shcherban A, Emtseva M, Efremova T. Molecular genetical characterization of vernalization genes $V r n-A 1, V r n-B 1$ and $V r n-D 1$ in spring wheat germplasm from Russia and adjacent regions. Cereal Res Commun. 2012; 40(3):351-61.

52. Fu D, Szűcs P, Yan L, Helguera M, Skinner JS, Von Zitzewitz J, et al. Large deletions within the first intron in VRN-1 are associated with spring growth habit in barley and wheat. Mol Gen Genomics. 2005;273(1):54-65.

53. Chu CG, Tan CT, Yu GT, Zhong S, Xu SS, Yan L. A novel retrotransposon inserted in the dominant Vrn-B1 allele confers spring growth habit in tetraploid wheat (Triticum turgidum L.). G3. 2011;1(7):637-45.

54. Fayaz F, Sarbarzeh MA, Talebi R, Azadi A. Genetic diversity and molecular characterization of Iranian durum wheat landraces (Triticum turgidum durum (Desf.) Husn.) using DArT markers. Biochem Genet. 2019;57(1):98116.

55. Mengistu DK, Kidane YG, Catellani M, Frascaroli E, Fadda C, Pé ME, et al. High-density molecular characterization and association mapping in Ethiopian durum wheat landraces reveals high diversity and potential for wheat breeding. Plant Biotechnol J. 2016;14(9):1800-12.

56. Zhang P, Dreisigacker S, Buerkert A, Alkhanjari S, Melchinger AE, Warburton ML. Genetic diversity and relationships of wheat landraces from Oman investigated with SSR markers. Genet Resour Crop Evol. 2006;53(7):1351-60.

57. Talbert $L E$, Smith $L Y$, Blake NK. More than one origin of hexaploid wheat is indicated by sequence comparison of low-copy DNA. Genome. 1998;41(3): 402-7.

58. López-Arias M, Grau-Corbí JM. Metales pesados, materia orgánica y otros parámetros de la capa superficial de los suelos agrícolas y de pastos de la España peninsular. II. Resultados globales. Madrid: INIA, MMA, MEC, MAPA; 2005.

59. Rodriguez-Quijano M, Vazquez JF, Carrillo JM. Variation of high molecular weight glutenin subunits in Spanish landraces of Triticum aestivum ssp. vulgare and ssp. spelta. J Genet Breed. 1990;44(2):121-6.

60. Giraldo P, Rodriguez-Quijano M, Simon C, Vázquez JF, Carrillo JM. Allelic variation in HMW glutenins in Spanish wheat landraces and their relationship with bread quality. Span J Agric Res. 2010;8(4):1012-23.

61. lqual M, Navabi A, Yang R, Salmon DF, Spaner D. The effect of vernalization genes on earliness and related agronomic traits of spring wheat in northern growing regions. Crop Sci. 2007:47(3):1031-9.

62. Cavanagh CR, Chao S, Wang S, Huang BE, Stephen S, Kiani S, et al. Genomewide comparative diversity uncovers multiple targets of selection for improvement in hexaploid wheat landraces and cultivars. Proc Natl Acad Sci U S A. 2013;110(20):8057-62.

63. Muller T, Schierscher-Viret B, Fossati D, Brabant C, Schori A, Keller B, et al. Unlocking the diversity of genebanks: whole-genome marker analysis of Swiss bread wheat and spelt. Theor Appl Genet. 2018;131(2):407-16.

64. Brambilla V, Gomez-Ariza J, Cerise M, Fornara F. The importance of being on time: regulatory networks controlling photoperiodic flowering in cereals. Front Plant Sci. 2017:8:665.

65. Soriano JM, Villegas D, Aranzana MJ, Garcia Del Moral LF, Royo C. Genetic structure of modern durum wheat cultivars and mediterranean landraces matches with their agronomic performance. PLoS One. 2016;11(8):e0160983.
66. Pujol J. Las innovaciones biológicas en la agricultura española antes de 1936: el caso del trigo, en Agricultura y Sociedad, 1998;86:163-184.

67. Xu X, Liu X, Ge S, Jensen JD, Hu F, Li X, et al. Resequencing 50 accessions of cultivated and wild rice yields markers for identifying agronomically important genes. Nat Biotechnol. 2012;30(1):105.

68. Yan L, Loukoianov A, Tranquilli G, Helguera M, Fahima T, Dubcovsky J. Positional cloning of the wheat vernalization gene VRN1. Proc Natl Acad Sci U S A. 2003;100(10):6263-8.

69. Hedden P. The genes of the green revolution. Trends Genet. 2003;19(1):5-9.

70. Aparicio N, Alvaro F, Sillero JC, Ruiz M, López P, Catedra MM, Codesal P. Bread wheat (Triticum aestivum L.) core collection based in Spanish landraces. Proceedings 8th International wheat conference. St. Petersburg: NI Vavilov Research Institute of Plant Industry; 2010. p. 85.

71. Doyle JJ, Doyle JL, Hortoriun LB. Isolation of plant DNA from fresh tissue. Focus. 1990;12:13-5.

72. Kilian A, Wenzl P, Huttner E, Carling J, Xia L, Blois H, et al. Diversity arrays technology: a generic genome profiling technology on open platforms. Methods Mol Biol. 2012;888:67-89.

73. Sansaloni C, Petrol C, Laccoud D, Carling J, Deterinh F, Grattapaglia D, Kilian A. Diversity Arrays Technology (DArT) and next-generation sequencing combined: genome-wide, high throughput, highly informative genotyping for molecular breeding of Eucalyptus. BMC Proceedings. 2011(5):54.

74. Chen F, Gao M, Zhang J, Zuo A, Shang X, Cui D. Molecular characterization of vernalization and response genes in bread wheat from the yellow and Huai Valley of China. BMC Plant Biol. 2013;13(1):199.

75. Zhang XK, Xiao YG, Zhang Y, Xia XC, Dubcovsky J, He ZH. Allelic variation at the vernalization genes Vrn-A1, Vrn-B1, Vrn-D1, and Vrn-B3 in Chinese wheat cultivars and their association with growth habit. Crop Sci. 2008;48(2):458-70.

76. Payne, P.I.; Law, C.N.; Mudd, E.E. Control by homoeologous group 1 chromosomes of the high-molecular weight subunits of glutenin, a major protein of wheat endosperm. Theor. Appl. Genet. 1980;58:113-120.

77. McIntosh RA, Yamazaki Y, Devos KM, Dubcovsky J, Rogers WJ, Appels R. Catalogue of gene symbols for wheat. Wheat Inf Serv. 2013;97:27-37.

78. R Core Team. R: a language and environment for statistical computing. 2014.

79. Rosenberg NA. DISTRUCT: a program for the graphical display of population structure. Mol Ecol Notes. 2004;4(1):137-8

80. Gruber B, Unmack PJ, Berry OF, Georges A. DARTR: an R package to facilitate analysis of SNP data generated from reduced representation genome sequencing. Mol Ecol Resour. 2018;18(3):691-9.

81. Nei M. Analysis of gene diversity in subdivided populations. Proc Natl Acad Sci. 1973;70(12):3321

82. Goudet J. Hierfstat, a package for R to compute and test hierarchical Fstatistics. Mol Ecol Notes. 2005;5(1):184-6.

83. Jost L. GST and its relatives do not measure differentiation. Mol Ecol. 2008; 17(18):4015-26.

84. Weir BS, Cockerham CC. Estimating F-statistics for the analysis of population structure. Evolution. 1984;38(6):1358-70

85. Pembleton LW, Pembleton ML. Package 'StAMP'; 2017.

\section{Publisher's Note}

Springer Nature remains neutral with regard to jurisdictional claims in published maps and institutional affiliations.

Ready to submit your research? Choose BMC and benefit from:

- fast, convenient online submission

- thorough peer review by experienced researchers in your field

- rapid publication on acceptance

- support for research data, including large and complex data types

- gold Open Access which fosters wider collaboration and increased citations

- maximum visibility for your research: over $100 \mathrm{M}$ website views per year

At BMC, research is always in progress.

Learn more biomedcentral.com/submissions 